\title{
Coarse-Scale Spatial Structure of Phytoplankton Standing Crop in Relation to Hydrography in the Open Baltic Sea
}

\author{
M. Kahru, A. Aitsam and J. Elken \\ Department of the Baltic Sea, Institute of Thermophysics and Electrophysics, Paldiski St. 1, Tallinn 200031, USSR
}

\begin{abstract}
During an interdisciplinary study of the BOSEX site in the Gotland Basin, central Baltic Sea, a number of mappings of the chlorophyll and hydrographic fields were made by vertical profilings on a regular grid of $20 \times 25$ nautical miles with a 5 -mile station spacing. Spatial variability of the chlorophyll and density fields was partitioned into the fine-scale $(-100 \mathrm{~m})$ and coarse-scale $(\sim 10 \mathrm{~km})$ components. The chlorophyll coarse-scale variance dominates over the fine-scale variance by an order of magnitude in the upper layer. The coarse-scale pattern of the phytoplankton standing crop, measured by the vertically integrated chlorophyll a concentration, shows 2.4 -fold variations and coupling to the pattern of the intermediate layer thickness. The intermediate layer separates the upper layer, suitable for plant growth, and the deep layer, the source of nutrients. It is suggested that above a thin intermediate layer, by increased vertical current shear and breaking internal waves, the upward flux of nutrients is intensified causing an enhanced phytoplankton growth and the increased standing crop.
\end{abstract}

\section{INTRODUCTION}

In recent years a considerable effort has been focussed on the spatial distribution of plankton in the aquatic environment (e.g. Steele, 1978). The study of plankton patchiness can provide a basis not only for a characterization of the variability which has important implications for any sampling programme, but also for an understanding of the functioning of the whole ecological system. Much of our recent development in the study of plankton variability has become possible by progress in measurement technology. Since the pioneering work of Platt (1972), the technique of in vivo fluorescence of chlorophyll a has extensively been used as the major method for investigations of the relative importance of physical and biological factors in the control of the pelagic phytoplankton distribution. The intrinsically three-dimensional nature of the marine system in general, and the phytoplankton variability in particular, makes it difficult to distinguish between different components of variability: temporal, horizontal and vertical. Although this is recognized (e.g. Denman and Mackas, 1978), the inherent methodological difficulties have confined most inves- tigators to one-dimensional (time or horizontal) or at best to two-dimensional horizontal mappings. The variability revealed is essentially contaminated by variability in other dimensions, e.g. vertical for horizontal surveys. A most important recent development has been the use of in situ sensors mounted on the undulating vehicle Batfish (Denman and Herman, 1978) which allows surveying in the vertical plane with spatial and temporal resolution inaccessible by other means.

We have used another approach. By vertical profilings on a regular grid we have obtained a quasisynoptic three-dimensional picture of the chlorophyll and hydrographic fields with a resolution below $1 \mathrm{~m}$ in the vertical and 5 nautical miles in the horizontal.

Attempts to understand the variability of primary production and phytoplankton in the sea in terms of the physical environment have usually met with limited success. A good exception is the work by Pingree and others (Pingree et al., 1978; Holligan and Harbour, 1977) who have elegantly related the phytoplankton growth around the British Isles to frontal transitions between well-mixed and stratified waters. We have obtained evidence that the coarse-scale $(10-30 \mathrm{~km})$ variations of the phytoplankton standing 
crop in the Baltic Sea are related to the similar scale variations of the physical structure which controls the flux of nutrients from the deep saline water.

The terms 'coarse-scale' for horizontal scales 1-100 km and 'fine-scale' for meters and hundreds of meters we adopted from Haury et al. (1978), although 'meso-scale' is more widely used for the first.

\section{MATERIALS AND METHODS}

Data were collected on several cruises of the RV 'Ayu-Dag' in 1979 and 1980 near the BOSEX site in the Gotland Basin, central Baltic Sea. The results of the 1979 surveys have been dealt with (Kahru, submitted) and an analysis of the seasonal trends is in preparation. Here we focus attention on the survey of 1-3 July, 1980. The station grid of 30 stations covered an area of $20 \times 25$ nautical miles $(37.0 \times 46.3 \mathrm{~km})$ with a 5 -mile $(9.3 \mathrm{~km})$ spacing. The mapping track passed the stations from Station 1 to Station 30 (Fig. 1). At each station, vertical profiles were taken while lowering and raising the profiler at the speed of $30 \mathrm{~cm} \mathrm{~s}^{-1}$. The

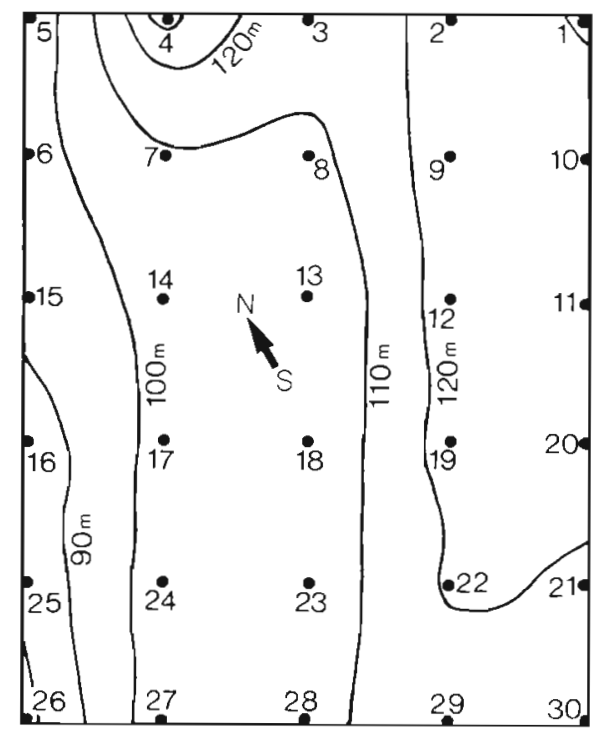

Fig. 1. Bathymetry and station grid. Station spacing is 5 nautical miles. Station 17 has co-ordinates $56^{\circ} 09.7^{\prime} \mathrm{N}, 18^{\circ} 35.7^{\prime} \mathrm{E}$

time interval between subsequent stations was $\simeq 1 \mathrm{~h}$ and the duration of the whole survey $\simeq 30 \mathrm{~h}$.

The profiler consisted of a Variosens in situ fluorometer (Impulsphysik, Hamburg) mounted on a Neil Brown Mark III CTD (conductivity-temperaturedepth) probe. The Variosens analog signal of the chlorophyll a fluorescence was digitized and, together with the CTD, interfaced to a Hewlett Packard 9825A minicomputer used for data acquisition, storage, processing, 'on line' plotting and contouring. As the fluorometer sampling volume is $\leqslant 1 \mathrm{~cm}^{3}$, fluctuations, caused by the random number of cells and their aggregations entering the sampling volume, are always present. To minimize their effect, the fluorescence signal was processed 'on line' by integrating digitally for $\simeq 0.7 \mathrm{~s}$. This procedure substitutes for the electronical integration (sample/hold) used by Herman and Denman (1977). At a rate of $=1.4 \mathrm{~Hz}$ (corresponding to depth interval $\approx 18 \mathrm{~cm}$ ) a data set, consisting of depth, temperature, salinity and chlorophyll fluorescence, was recorded.

As the in vivo fluorescence per unit chlorophyll $a$ is variable (Kiefer, 1973; Loftus and Seliger, 1975), frequent calibrations are needed. The calibration equation used for the Variosens signal is $C=a_{0}+a_{1} \exp \left(a_{2}\right.$ $\mathrm{V})$, where $\mathrm{C}$ is the chlorophyll a concentration, $\mathrm{V}$ is the fluorometer output, and $a_{0}, a_{1}, a_{2}$ are tunable coefficients. The coefficient $a_{2}$ depends only on the receiver amplification characteristics. It was determined with high precision using successive dilutions of a phytoplankton culture. $a_{0}$ and $a_{1}$ were determined by comparing the fluorescence with conventional spectrophotometric method of measuring extracted chlorophyll (Jeffrey and Humphrey, 1975). Water samples for the pigment and nutrient analyses were taken from Niskin bottles tripped at various depths at selected stations. Nitrate values were uniformly low in the upper and intermediate layers and will not be reported

For 30 samples taken at depths from 0 to $32 \mathrm{~m}$, the linear correlation between extracted chlorophyll and estimates from fluorescence was 0.96 . The mean standard error of the estimate was below $0.33 \mathrm{mg} \mathrm{m}^{-3}$. This is a fairly good coincidence if the differences in the sampling by the profiler and the Niskin bottles: time delay, vertical deviation and horizontal displacement during drift, are taken into account.

Herman (1977) observed abundant noise spikes on the Variosens chlorophyll signal which he attributed to the interference of zooplankton. The number of the spikes on our profiles was highly variable, but always higher on down-casts. We do not use a coarse mesh as Herman did, although it eliminates many of the spikes, because it can alter the water flow past the sensor. We eliminate the error spikes by 'off line' processing. Smoothing a chlorophyll profile with the cosine filter, we eliminate all the points exceeding the smoothed version by more than $1 \mathrm{mg} \mathrm{m}^{-3}$. The remaining points were averaged for $0.5 \mathrm{~m}$ depth intervals from the surface to $60 \mathrm{~m}$.

Maps of spatial distribution were constructed by the computer using a method called 'objective analysis (Gandin, 1965). 


\section{RESULTS}

Vertical thermohaline structure, typical of the Baltic Sea proper in the summer, is presented in Fig. 2. For the ease of discussion, the water column is divided into 3 layers: upper, intermediate and deep. The 2 prominent peaks in the Brunt-Väisälä frequency, separating the layers, are associated with a sharp drop in temperature and with a sharp increase in salinity, respectively.

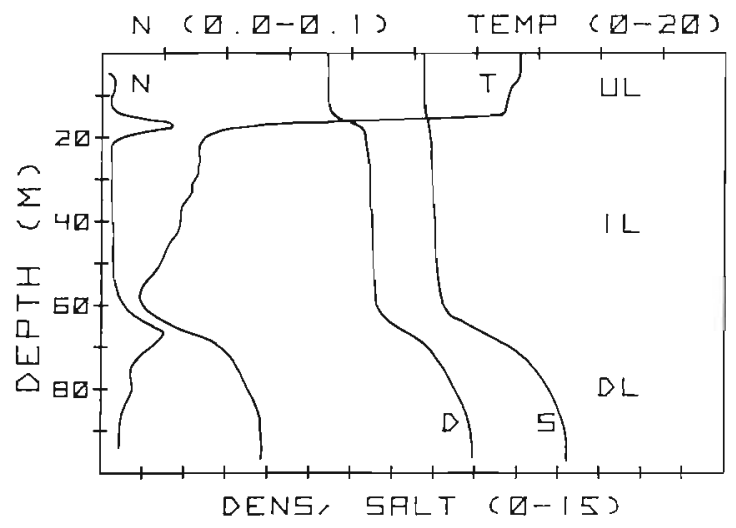

Fig. 2. Typical thermohaline structure with plots of temperature $\left(T,{ }^{\circ} \mathrm{C}\right)$, salinity $(\mathrm{S}, \%)$, density (D, sigma-t), and BruntVäisälä frequency $\left(\mathrm{N}, \mathrm{rad} \mathrm{s}^{-1}\right)$. The water column is divided into 3 layers: upper (UL), intermediate (IL), deep (DL)

The nutricline is associated with the base of the intermediate layer with nitrate nitrogen below $0.1 \mu \mathrm{g}$ atom $1^{-1}$ above it.

The vertical chlorophyll profiles of the survey are shown in Fig. 3. The subsurface chlorophyll maximum near the temperature drop is a consistent summer-time feature in the Baltic (Kahru, 1981). A prominent subsurface chlorophyll peak $\left(6 \mathrm{mg} \mathrm{m}^{-3}\right)$ existed at Station 14.

The means of the up-and down-cast profiles (Fig. 4) reveal a feature pertinent to a response characteristic of the fluorometer. The Variosens temperature independence is not complete when the instrument rapidly traverses a sharp temperature drop (up to $10^{\circ} \mathrm{C} \mathrm{m}^{-1}$ ). Consequently, the down-cast fluorescence is biased towards lower values immediately after the sharp drop in temperature. On up-casts, the temperature control is effective. Up-casts also contain less error spikes which are to be eliminated. Unless stated otherwise, we have used up-cast profiles to estimate the chlorophyll content.

Up- and down-casts show notable differences not attributable to any of methodological errors; rather, they result from small-scale spatial variability. The time delay between a down-and up-cast $(\simeq 10$ min at the surface), because of the drift, corresponds to about 100-200 m, i.e. to the horizontal fine-scale. We assume

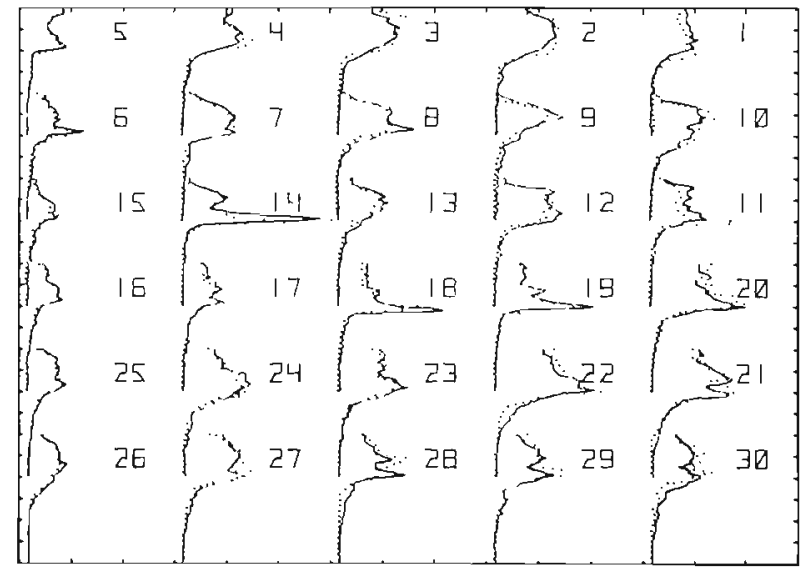

Fig. 3. Vertical profiles of chlorophyll $a$ on the survey area on up-casts (solid line) and down-casts (dotted line), Units on the axes are: $10 \mathrm{~m}$ in the vertical and $2 \mathrm{mg} \mathrm{Chl} \mathrm{a} \mathrm{m} \mathrm{m}^{-3}$ in the horizontal. Profiles are shifted according to their location on the grid (Fig. 1)

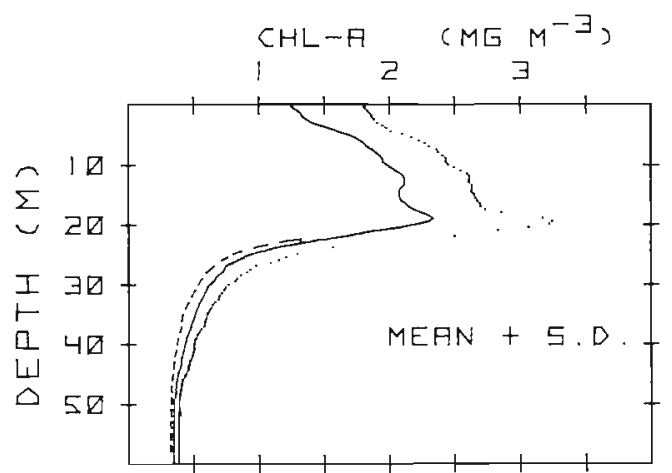

Fig. 4. Mean chlorophyll profiles recorded on up-casts (solid line), down-casts (dashed line), and the up-cast mean + standard deviation (dotted line)

that the total variance of an individual chlorophyll profile, $\sigma_{T}{ }^{2}(z)$, has two components, i.e.

$$
\sigma_{T}^{2}(z)=\sigma_{W}{ }^{2}(z)+\sigma_{B}^{2}(z) .
$$

where $z$ is the vertical co-ordinate, $\sigma_{W}{ }^{2}$ is the within station variance (between up- and down-casts), and $\sigma_{B}{ }^{2}$ is the between station variance. In other terms, we have divided the total variance into the fine-scale $(\sim 100 \mathrm{~m})$ and coarse-scale $(\sim 10 \mathrm{~km})$ components. $S_{W}$, the estimate of $\sigma_{w}^{2}$, also contains the error variance, caused by shifts in the instrument response characteristics, ambiguities in places where spikes were eliminated, etc. The analysis of variance model is essentially the same as used by Platt et al. (1970) and Therriault and Platt (1978). The important difference is that we can trace the vertical trends of the variances. To guarantee normality, the data were transformed by $\log (x+1)$ before the analysis of variance was made. The estimated components of variance, $S_{W}$ and $S_{B}$, show discernible vertical variation (Fig. 5). Both reach 


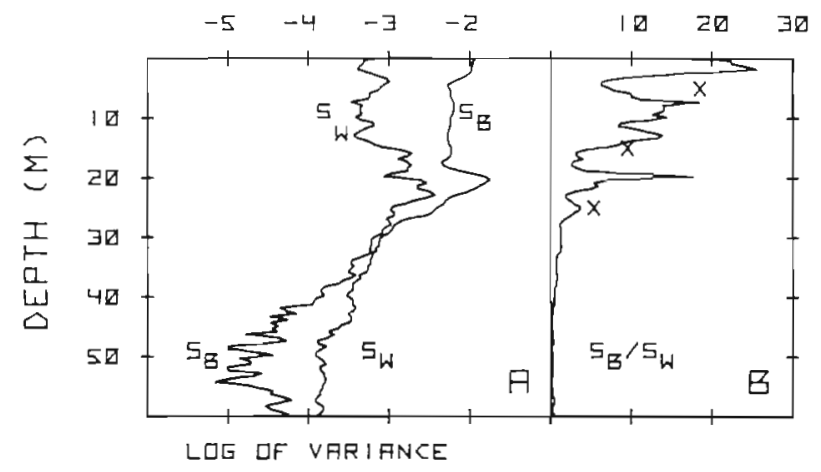

Fig. 5. Vertical plots of coarse-scale variance $\left(S_{B}\right)$ and finescale variance $\left(S_{W}\right)$ of chlorophyll a concentration (A); and their ratio, $S_{B} / S_{W}$ (B). Crosses show the ratios for integrated concentrations in 10-m layers

their maxima in the subsurface chlorophyll maximum. $S_{B}$ has an additional maximum near the surface. The ratio $S_{B} / S_{W}$ exceeds 20 in the near-surface layer and 15 in the subsurface chlorophyll maximum. The $S_{W}$ high values below $25 \mathrm{~m}$ are certainly artifacts, resulting from the temperature response of the fluorometer as discussed above. The $S_{W}$ curve should not perhaps exceed the $S_{B}$ curve (it does below $33 \mathrm{~m}$ ). In spite of the methodological problems, the existence of a significant coarse-scale variance is proved down to $40 \mathrm{~m}$ and is probable down to the bottom.

To get a hint how much of the chlorophyll variance may be a direct consequence of short-term vertical displacements, e.g. by internal waves, we applied exactly the same procedure to density profiles (Fig. 6). The $S_{W}$ maximum on the temperature discontinuity at $20 \mathrm{~m}$ is attributable to the effect of internal waves. However, as the estimate of the coarse-scale variance exceeds the fine-scale density variance by an order of magnitude, processes other than short-period internal waves must be dominating. It is particularly evident above $15 \mathrm{~m}$ with the $S_{B} / S_{W}$ ratio exceeding 30 , where most of the variance is produced by differential wind mixing, entrainment and solar heating. Intrusions,

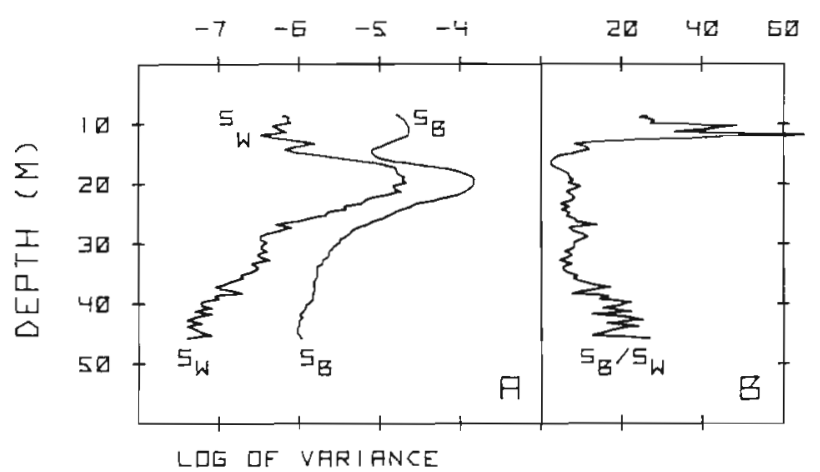

Fig. 6. Vertical plots of coarse-scale variance $\left(S_{B}\right)$ and finescale variance $\left(S_{W}\right)$ of density $(A)$; and their ratio, $S_{B} / S_{W}(B)$ meso-scale eddies, rising and lowering of isopycnals as a result of geostrophic balance cause most of the density variance below $15 \mathrm{~m}$.

Studies of the thermohaline fine structure (Fedorov, 1978) have shown that thermohaline structures have a ratio of their horizontal to vertical extent of the order of $10^{3}-10^{4}$. Assuming $10^{3}$ as the upper limit for chlorophyll layers, the appropriate vertical scale for coarse-scale horizontal structures is at least $10 \mathrm{~m}$. Previous studies (Denman, 1977) and our previous results have indicated that, due to the fine-scale vertical and horizontal chlorophyll variability, chlorophyll concentration at a fixed depth, the most commonly used parameter, is a poor indicator of the coarse-scale structure and changes in the whole chlorophyll layer. Therefore, we use integrated concentrations for 10 -m thick layers as relevant coarse-scale parameters. Integrated concentrations do have lower fine-scale variability, i.e. higher $S_{B} / S_{W}$ ratio, when compared with fixed depth measurements in the same layer (Table 1). Unexpectedly, the extreme $S_{B} / S_{W}$ ratios of some fixed depth measurements exceed the same ratio for integrated concentrations (Fig. 5).

The distribution patterns of chlorophyll concentration were generally similar between most of the $10-\mathrm{m}$ layers. The total chlorophyll, i.e. the integral between 0 and $60 \mathrm{~m}$, is weakly influenced by distribution below $40 \mathrm{~m}$. Distribution maps of the total chlorophyll and the 'deep' chlorophyll are shown in Figs. 7 and 8 . The general pattern is characterized by a high concentration patch with horizontal dimensions $\simeq 10 \mathrm{~km}$ (St. 20 , $21,22)$ and a frontal discontinuity in the total chlorophyll along the whole north-western edge of the area. The across front differences at the distance of $13 \mathrm{~km}$ reach the factor of 1.8 in the total chlorophyll (St. 24:77; St. 16:43 $\mathrm{mg} \mathrm{m}^{-2}$ ). Maximal differences in the area reach 2.4 -fold in the total chlorophyll and 2.8-fold in the upper $30 \mathrm{~m}$.

The survey area with its predominantly NW-SE isobaths approximates a canyon which directs the current in the deep and intermediate layers. The geostrophic method (Pond and Pickard, 1978) allows to be estimated the baroclinic flow pattern in the area due to the Coriolis force, isopycnals get inclined to the geopo-

Table 1. Comparison of ratios of coarse-scale variance to finescale variance $\left(S_{B} / S_{W}\right)$ of chlorophyll concentration. Vertically integrated concentrations and the means for fixed depth concentrations

\begin{tabular}{|ccc|}
\hline Depth $(\mathrm{m})$ & Integrated & Fixed depth \\
\hline $0-10$ & 18.4 & 14.1 \\
$10-20$ & 9.4 & 7.8 \\
$20-30$ & 5.3 & 3.2 \\
\hline
\end{tabular}




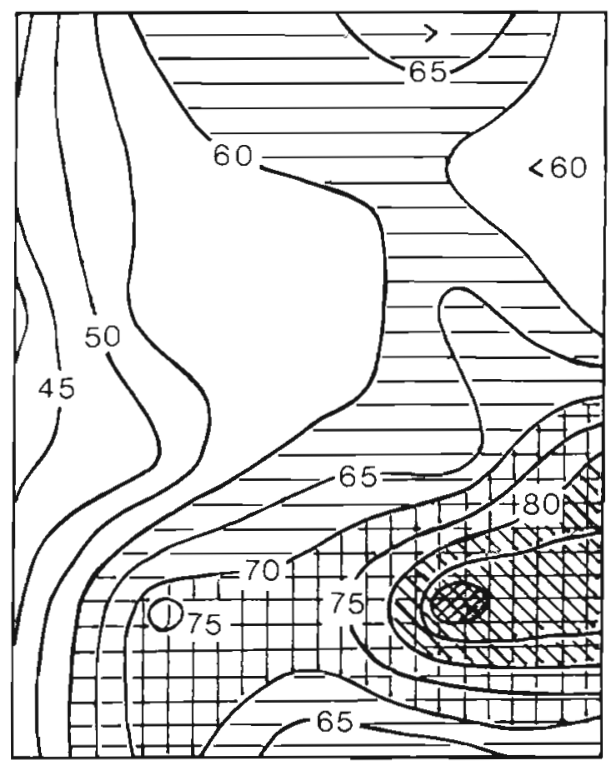

Fig. 7. Map of the total chlorophyll (integral of the Chl a concentration between $0-60 \mathrm{~m}$ ) in $\mathrm{mg} \mathrm{m}^{-2}$

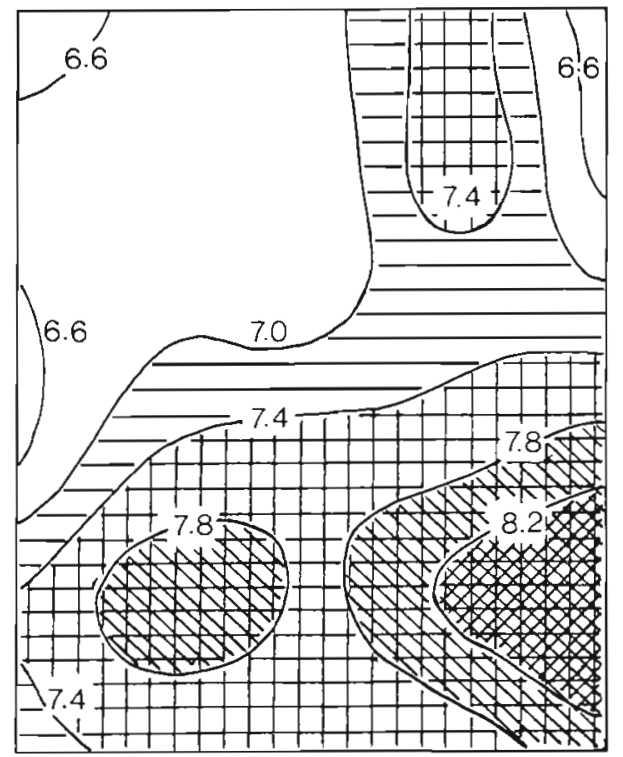

Fig. 8. Map of the deep chlorophyll (integral of the Chl a concentration between $40-60 \mathrm{~m}$ ) in $\mathrm{mg} \mathrm{m}^{-2}$ The small positive anomaly in the upper part (isopleth 7.4) is probably caused by upward velocities in the cyclonic eddy

tential level surfaces, sloping up to the left (north-east) if one looks in the direction of the current. The geostrophic balance resulted in the inclined isopycnals and increased thickness of the intermediate layer along the NW edge of the area (Fig. 9). The dynamic topography (map of geopotential distances) between the 70 and 30-dbar pressure surfaces (Fig. 10) shows the flow pattern of the 30 -dbar level relative to the 70 -

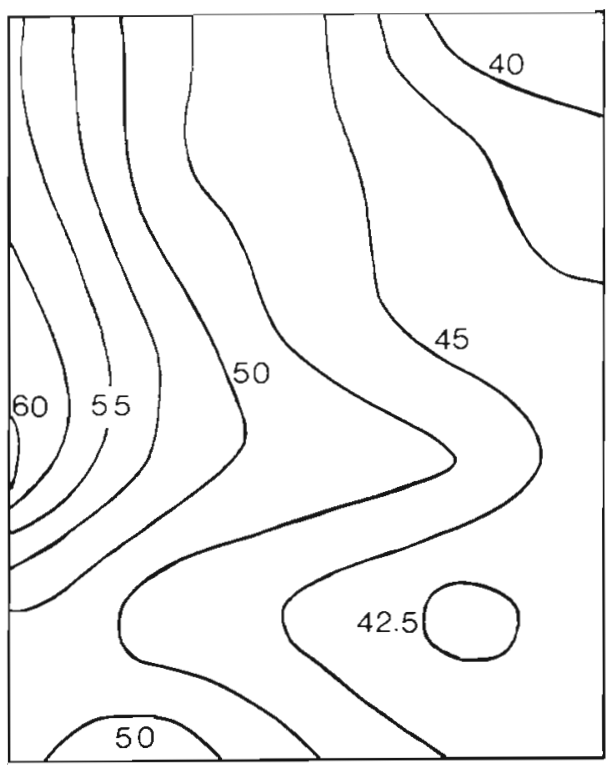

Fig. 9. Map of the intermediate layer thickness in meters

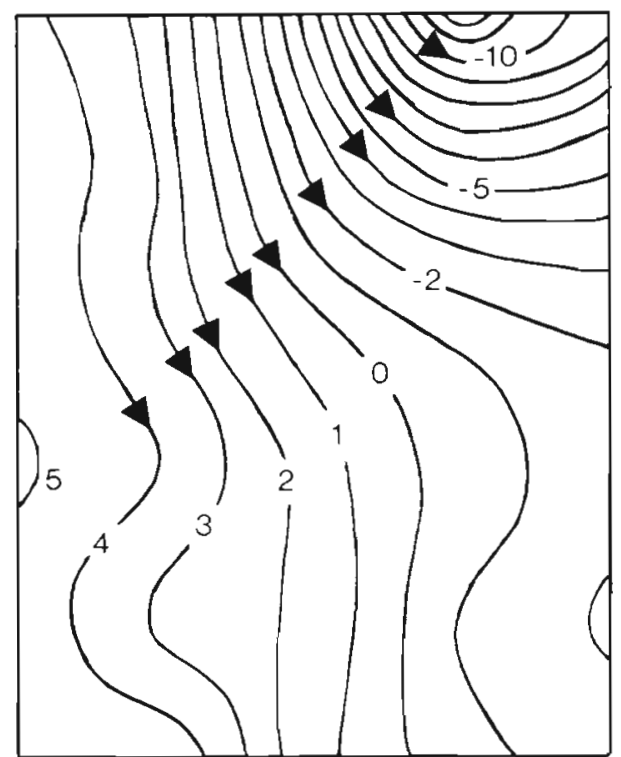

Fig. 10. Map of the relative dynamic topography (deviations from the mean) between the 70 and 30-dbar levels in 0.001 dyn $m$. Arrows show estimated current direction

dbar level (i.e. the flow of the intermediate layer relative to the deep layer)

Trying to correlate the chlorophyll pattern with the hydrography, we calculated the correlation matrix between several variables (Table 2). As could be expected, the chlorophyll levels in the layers are positively correlated between each other. The chlorophyll concentrations are positively correlated with the upper layer thickness and negatively with the deep layer depth, i.e. negatively with the intermediate layer 
Table 2. Correlation coefficients between integrated chlorophy]l, a concentrations in different layers (depths, m), upper layer thickness (ULT), deep layer depth (DLD), and intermediate layer thickness (ILT). The requirement of significance on the P $<0.05$ level is 'r. $\geqslant 0.42$

\begin{tabular}{|rrrrrrrrr}
\hline & $0-10$ & $10-20$ & $20-30$ & $30-40$ & $40-50$ & $50-60$ & $0-60$ & ULT \\
\hline $10-20$ & 0.81 & & & & & & & \\
$20-30$ & 0.65 & 0.72 & & & & & \\
$30-40$ & 0.61 & 0.60 & 0.77 & & & & \\
$40-50$ & 0.56 & 0.55 & 0.71 & 0.87 & & & \\
$50-60$ & 0.41 & 0.49 & 0.61 & 0.64 & 0.80 & & & \\
D-60 & 0.89 & 0.93 & 0.88 & 0.78 & 0.72 & 0.61 & & \\
ULT & 0.34 & 0.34 & 0.45 & 0.44 & 0.37 & 0.26 & 0.43 & -0.17 \\
DLD & -0.58 & -0.55 & -0.37 & -0.23 & -0.24 & -0.26 & -0.54 & -0.48 \\
ILT & -0.63 & -0.60 & -0.48 & -0.35 & -0.34 & -0.32 & -0.62 & 0.94 \\
\hline
\end{tabular}

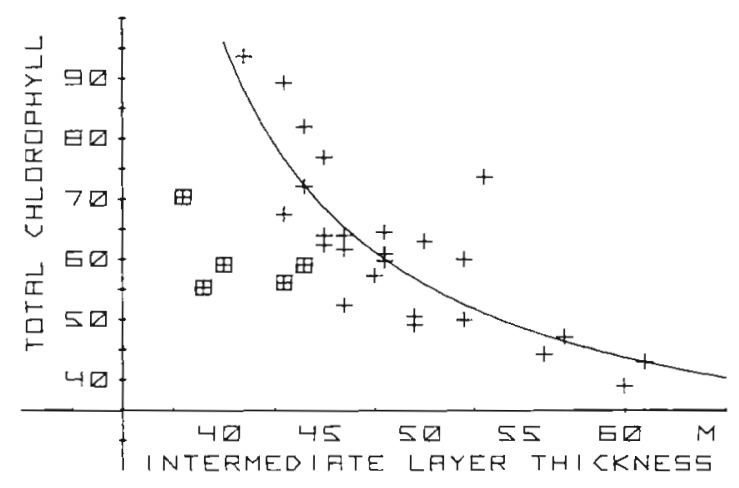

Fig. 11. Dependence of the total chlorophyll $\left(\mathrm{mg} \mathrm{m}^{-2}\right)$ on the intermediate layer thickness $(\mathrm{m})$. The circled points are from the NE corner with the cyclonic eddy. They have been excluded when fitting the curve $Y=1 /(0.05-1.50 / X)$ by least squares

thickness. Positive correlation with the upper layer thickness implies that the upper layer is not much thicker than the euphotic zone, otherwise the phytoplankton standing crop would decrease due to mixing into the aphotic zone. Derived from the Secchi disc values, the compensation depth was between 15 and $20 \mathrm{~m}$. The upper layer is, however, well-mixed only after storms. The dependence of the total chlorophyll on the intermediate layer thickness is shown in Fig. 11. The increased phytoplankton standing crop is probably effectuated by an intensified vertical mixing at localities with a thin intermediate layer. Mixing by breaking internal waves or shear induced turbulence should be accompanied by intermittent density inversions. The number of density inversions between 20 and $60 \mathrm{~m}$ of at least 0.005 sigma-t units and at least $0.5 \mathrm{~m}$ vertical extent was highly variable, ranging from 0 to 10 , and did not show significant correlations with other variables studied. As density inversions are ephemeral, the observed inversions need not be representative of strong mixing in the past. On the other hand, we suggest that the response of the phytoplankton standing crop to increased mixing has a time delay of at least some days. The four points with the strongest deviations from the fitted line in Fig. 11 all originate from the NE corner of the area (St. 1, 2, 9, 10) where an eddy-like disturbance was observed (Fig. 10). The location of the cyclonic eddy coincided with a small positive anomaly in the deep water chlorophyll concentration (Fig. 8). The upward velocities within the cyclonic eddy had probably reduced or even overridden the phytoplankton sinking tendency, bringing about the accumulation.

\section{DISCUSSION}

To guarantee that a mapping of the chlorophyll and hydrographic fields is at least quasi-synoptic, processes on shorter time scales than the duration of the survey $(30 \mathrm{~h})$ must not dominate the measurements. Vigorous short-term changes in the chlorophyll and nutrient concentrations take place during the spring outburst (Hobro et al., in press), but are not expected to occur during stable summer conditions when the system has reached a certain degree of stationarity. Chlorophyll content may show short-term variations caused by synthesis, grazing and destruction (Harris, 1980). Diel variations in the chlorophyll fluorescence have been observed (Kiefer, 1973; Karabashev and Solovyev, 1977; Prézelin and Ley, 1980), particularly in subtropical and tropical areas, showing inhibition at high illumination. Using the analysis of variance, we were unable to detect any significant diel changes in fluorescence intensity or in the fluorescence/extracted chlorophyll ratio on any of the surveys. While the existence of diel fluctuations cannot be denied, they probably do not effect the first order estimate of the coarse-scale chlorophyll pattern. This is indicated by the high correlation between fluorescence and extracted chlorophyll. Further evidence, that the observed pattern is not dependent on short-term changes, was obtained by 2 successive surveys made at 
a 10 d interval in 1979 (Kahru, submitted). Persistence of the general pattern against the background of discernible tendencies became evident.

Platt et al. (1970) examined the variance of a fixed number of chlorophyll measurements dispersed over areas of different sizes in an exposed bay. The variance between stations increased rapidly as the area was increased and remained approximately constant for areas $>2.5 \mathrm{~km}^{2}$. We have shown that in the open Baltic Sea, the coarse-scale $(\sim 10 \mathrm{~km})$ chlorophyll variance clearly dominates over the fine-scale $(\sim 100 \mathrm{~m})$ component. The fine-scale variability is, however, impressive, as compared with the density variability, and should always be considered in point sampling monitoring studies. Although we were unable to resolve properly the intermediate scales, the unambiguous pattern in the chlorophyll distribution maps confirms the dominance of bigger scales of variability. We conjecture that the bigger scales of variability in the Baltic when compared with Platt et al. (1970) are caused by the difference between a pelagic and a coastal environment. Many studies (e.g. Steele and Henderson, 1979) concentrate on continuous measurements along transects at a fixed depth. As discussed above, the vertically integrated concentrations, instead of the concentration at a fixed depth, should be used for assessing the coarse-scale horizontal variability.

A drastic influence of an unusual mixing event on the rate of primary production and zooplankton standing crop in the North Pacific central gyre was demonstrated by McGowan and Hayward (1978). We have presented evidence for a strong coupling between the intermediate layer thickness and the phytoplankton standing crop in the Baltic. We suggest that at localities with a thin intermediate layer, increased current shears and internal waves interact to produce a local concentration of energy which may be released for mixing. Uniformly low nitrate levels above the deep layer suggest that the temperature discontinuity between the upper and the intermediate layers is not effective in blocking the upward flux of nutrients. Physical evidence for a rapid erosion of the thermocline in the Baltic Sea was presented by Krauss (1978). Crucial to the detection of the vertical mixing is whether it is a continuous process or a result of infrequent individual events. Woods (1977) has suggested that internal mixing in stratified conditions is essentially an intermittent process occurring on small scales. Further studies are needed to explicate the existence, causes and the ecological consequences of localized vertical mixing.

Acknowledgements. We acknowledge the assistance and help by R. Portsmuth, O. Bekasova, K. Oja, K. Lust and T. Kullas.

\section{LITERATURE CITED}

Denman, K. L. (1977). Short term variability in vertical chlorophyll structure. Limnol. Oceanogr 22: 434-441

Denman, K. L., Herman, A. W. (1978). Space-time structure of a continental shelf ecosystem measured by a towed porpoising vehicle. J. mar. Res. 36: 693-714

Denman, K. L., Mackas, D. L. (1978). Collection and analysis of underway data and related physical measurements. In: Steele, J. H. (ed.) Spatial pattern in plankton communities. Plenum Press, New York, pp. 85-109

Fedorov, K. N. (1978). The thermohaline fine structure of the ocean, Pergamon Press, Oxford

Gandin, L. S. (1965). Objective analysis of meterological fields, Israel Program for Scientific Translations, Jerusalem

Harris, G. P. (1980). Temporal and spatial scales in phytoplankton ecology. Mechanisms, methods, models, and management. Can. J. Fish. Aquat. Sci. 37: 877-900

Haury, L. R., McGowan, J. A.. Wiebe, P. H. (1978). Patterns and processes in the time-space scales of plankton distributions. In: Steele, J. H. (ed.) Spatial pattern in plankton communities. Plenum Press, New York, pp. 277-327

Herman, A. W. (1977). In situ chlorophyll and plankton measurements with the Batfish vehicle. Oceans '77, Oct. 1977, Los Angeles, Calif. Session 39: Instrumentations for biological measurements

Herman, A. W., Denman, K. L. (1977). Rapid underwater profiling of chlorophyll with an in situ fluorometer mounted an a 'Batfish' vehicle. Deep Sea Res. 24: 385-397

Hobro, R. Larsson, U., Wulff, F. (in press). Dynamics of phytoplankton spring bloom in a coastal area in the Northern Baltic. Pr morsk. Inst. ryb. Gdyni

Holligan, P. M., Harbour, D. S. (1977 The vertical distribution and succession of phytoplankton in the western English Channel in 1975 and 1976. J. mar biol. Ass. U. K. 57: 1075-1093

Jeffrey, S. W., Humphrey, G. F. (1975). New spectrophotomet ric equations for determining chlorophylls $a, b, c_{1}$ and $c_{2}$ in higher plants, algae and natural phytoplankton. Biochem. Physiol. Pflanzen (BPP) 167: 191-194

Kahru, M. (1981). Relationships of chlorophyll maxima to density structure in the Baltic Sea. Oceanology 21: 112-117

Kahru, M. (1981). Variability in the three-dimensional structure of the chlorophyll field in the open Baltic Sea Oceanology 21, submitted

Karabashev, G. S., Solovyev, A. N. (1977). Spatial and temporal variability of pigment fluorescence in living phytoplankton cells. Polskie Arch. Hydrobiol. 24: 201-213

Kiefer, D. A. (1973). Fluorescence properties of natural phytoplankton populations. Mar. Biol. 22: 263-269

Krauss, W. (1978). Inertial waves and mixing in the thermocline (BOSEX-Results). Proc. 11 Conf. Baltic Oceanographers, Rostock, 24-27 April 1978, 2: 709-728

Loftus, M. E., Seliger, H. H. (1975). Some limitations of the in vivo fluorescence technique. Chesapeake Sci. 16: 79-92

McGowan, J. H., Hayward, T L. (1978). Mixing and oceanic producitivity. Deep Sea Res. 25: 771-793

Pingree, R. D., Holligan, P. M., Mardell, G. T. (1978). The effects of vertical stability on phytoplankton distributions in the summer on the northwest European Shelf. Deep Sea Res. 25: 1011-1028

Platt, T. (1972). Local phytoplankton abundance and turbulence. Deep Sea Res. 19: 183-187

Platt, T., Dickie, L. M., Trites, R. W (1970). Spatial 
heterogeneity of phytoplankton in a near-shore environment. J. Fish. Res. Bd Can. 27: 1453-1473

Pond, S., Pickard, G. L. (1978). Introductory dynamic oceanography, Pergamon Press, Oxford

Prézelin, B. B., Ley, A. C. (1980). Photosynthesis and chlorophyll a fluorescence rhythms of marine phytoplankton. Mar Biol. 55: 295-307

Steele, J. H. (ed.) (1978). Spatial pattern in plankton communities, Plenum Press, New York
Steele, J. H., Henderson, E. W (1979). Spatial patterns in North Sea plankton. Deep Sea Res. 26A: 955-963

Therriault, J.-C., Platt, T (1978). Spatial heterogeneity of phytoplankton biomass and related factors in the nearsurface waters of an exposed coastal embayment. Limnol. Oceanogr 23: 888-899

Woods, J. D. (1977). Parameterization of unresolved motions. In: Kraus, E. B. (ed.) Modelling and prediction of the upper layers of the ocean. Pergamon Press, Oxford, pp. 118-140

This paper was presented by Dr. T Platt; it was accepted for printing on April 27, 1981 